\title{
Okul Öncesi Öğretmen Adaylarının Çocuk Sevme Eğilimlerinin İncelenmesi
}

\author{
The Examination of Pre-Service Preschool Teachers' Towards Liking Children
}

Zeliha YAZICI*

Özet: Okul öncesi dönem, çocuğun ilköğretim yıllarına kadar temel gelişimsel ve eğitimsel ihtiyaçlarının karşılandığı zaman dilimidir. Bu süreçte, karşılanması gereken en temel gereksinim sevgi ve ilgi ihtiyacıdır. Bu çalışma, çocukların tüm gelişim alanlarında ve temel öğrenmelerinde büyük bir öneme sahip olan okul öncesi öğretmen adaylarının çocuk sevme eğilimlerini incelemek amacıyla yapılmıştır. Araştırmanın çalışma gurubunu 2011-2012 Eğitim öğretim yılında Akdeniz Üniversitesi ve Çukurova Üniversitesi'nin Eğitim Fakültesi Okul Öncesi Öğretmenliği Lisans Programı öğrencileri oluşturmaktadır. Örneklemini ise Akdeniz Üniversitesi’nden 320, Çukurova Üniversitesi'nden 290 olmak üzere toplam 610 öğretmen adayı oluşturmaktadır. Veri toplama aracı olarak, araştırmacı tarafından hazırlanmış kişisel bilgi formu ve Barnett, \& Sinisi (1990) tarafından insanların çocuklara yönelik tutumlarını ölçme amacıyla geliştirilen, Duyan, \& Gelbal (2008) tarafından Türkçe’ye uyarlanan Barnett, Çocuk Sevme Ölçeği kullanılmıştır. Araştırmanın istatistiksel analizi için değişkenlerin yapısına ve verilerin özelliklerine uygun olacak şekilde parametrik ve parametrik olmayan istatistiksel yöntemlerden faydalanılmıştır. Araştırmadan elde edilen bulgulara göre, okul öncesi öğretmen adaylarının çocuk sevme eğilimlerinin cinsiyete, yaş ve sınıf düzeyine göre farklılıklar gösterdiği görülmüştür.

Anahtar sözcükler: Çocuk sevme eğilimi, okul öncesi, öğretmen özellikleri, öğretmen-çocuk

Abstract: Preschool is a period when basic developmental and pedagogical needs are supplied before primary school. In this process, the most basic requirements, which should be addressed, are affection and care. In this study, we aimed to investigate the aptitude of candidate preschool educators; their liking children which has great importance on children's basic learning and in every developmental field. This study's target population included faculty of education preschool teaching undergraduate students of Akdeniz University and Çukurova University in the 2011-2012 academic year. Sampling consisted of 610 teacher candidates, 320 from Akdeniz University, 290 from Çukurova University. As a measuring instrument, Barnett liking of children scale which was adapted by Duyan, \& Gelbal (2008), as developed by Barnett, \& Sinisi, (1990) to measure peoples' attitude towards children was employed. Statistical methods, which are suitable for the features and structures of variables as parametric and non-parametric, are used for statistical analysis of the research. According to the results obtained from the study of children liking scores, the teachers' gender, age and grade level were found to be factors.

Keywords: Liking children, preschool time, teacher characteristics, teacher-child

\section{Giriş}

Küreselleşen dünya düzeninde yeniden yapılanmalar oluştukça, toplumların da bu hızlı değişime uyum sağlaması gerekmektedir. Bireylerin bu yapılanmalara uyum sağlayabilmesi nitelikli eğitim sistemleriyle gerçekleşebilmektedir. Kaliteli ve nitelikli insan gücü yetiştirmeyi amaçla-

\footnotetext{
*Yrd. Doç. Dr. Akdeniz Üniversitesi, Eğitim Fakültesi, İlköğretim Bölümü, Antalya, zyazici@akdeniz.edu.tr
} 
yan her toplumun eğitim sisteminin en temel yapı taşı da öğretmenlerdir.

Öğretmenin sahip olacağı nitelikler toplumsal bilincin niteliğini etkileyeceğinden; öğretmenlerden eğitim-öğretimi yönetme, öğrenenin gelişim sürecini ve öğretimin kalitesinin değerlendirme gibi mesleki beceriler beklenmektedir (Özsoy, vd., 2010). Bu beklentileri gerçekleştirecek kaliteli ve nitelikli öğretmenlerin yetiştirilmesi için iki temel nokta ön planda tutulmaktadır. Bu temel noktalardan birincisi mesleki özelliklerin kazandırılmasını amaçlayan alan bilgisi, genel kültür ve öğretmenlik meslek bilgisidir (Kavcar, 2002). Mesleki yeterlilik olarak adlandırılan bu beceriler, nitelikli bir eğitim için öğretmenlerin yetiştirilmesinde gerekli görülen en temel becerilerdir (Tomlinson,1995). İkincisi ise öğretmenlere kişisel yeterlilikleri kazandırmayı amaçlayan mesleki yatkınlık ve öğretmenlik modeli olma gibi bireysel becerilerdir (Kavcar, 2002). Kaliteli öğretmen yetiştirme felsefesinden hareketle her iki öğeyi ön plana çıaran öğretmen yetiştirme programlarının en genel amacı, öğretmen adaylarına bir işte neyin, ne zaman ve nasıl yapılması gerektiği hususunda ayrım yapabilme becerilerini içeren mesleki ya da bireysel yeterliliklerin kazandırılmasıdır. Bu nedenle öğrenci kitlesinin akademik ve toplumsal yaşama uyumlarında önemli rol alacak olan öğretmen adaylarının, öğretmenlik mesleğinin görev ve sorumluluklarını yerine getirebilmeleri için mesleki yeterlilikleri (Tomlinson, 1995) kadar mesleki yatkınlığı ve mesleğini sevmesi (Demirel, 2006) de son derece önemlidir.

Öğretmenlerin mesleğini uzun süre tükenmişlik yaşamadan icra edebilmeleri için hizmet edecekleri kitleyi önceden kabullenmeleri ve sevmeleri gerekmektedir. Bu nedenle öğretmen yetiştirmede gerek mesleki yeterliliği kazanabilecek düzeyde sosyal, duygusal ve akademik becerileri kazanmaya yatkınlık gerek alana karşı ilgi ve isteklilik önemli ölçütler olmalıdır (Weinstein, 1988). Birçok araştırmada öğretmenlerin kaliteli bir eğitim gerçekleştirebilmesi için sahip olduğu mesleki yeterliliklerin yanında özellikle çocuklarla çalışmayı sevmesi gerektiği vurgulanmaktadır (Lasley, 1980; Veenman, 1984; Marso, \& Pigge 1994; Downing et alii 2000). Eskicumali (2002), öğretmenlik mesleğini seçmenin en temel nedenlerinden birinin çocukları sevmek olduğunu belirtirken, Gelbal, \& Duyan (2010)'nın aktarımlarında da çocuklarla çalışmak için en önemli değişkenin çocukları sevmek olduğu vurgulanmaktadır.

Öğretimin her aşamasında öğretmenin çocuklar üzerinde etkisi olduğu bilinmektedir. Öğretmelerin çocukla etkileşiminin çocuğun gelişimine olan etkileri bağlanma teorisi, bilişsel teoriler ve sosyo-ekolojik teorilerinde de vurgulanmaktadır. Bu farklı yaklaşımlarda da belirtilen ortak nokta, çocukların okula uyumunda en önemli etkenin çocuğun öğretmenle kuracağı iletişimin kalitesi yönündedir (Hughes et alii, 1999). Okul öncesi dönemdeki çocuk, sosyal anlamda güven duyduğu aile ortamından sonra okul gibi karmaşık sosyal bir alana girdiğinde öncelikle öğretmen ve akranlarının karmaşık istekleri ile karşı karşıya kalmakta ve bu durum çocuğun okuldaki sosyal uyum davranışları açısından önemli bir sorun olabilmektedir (Anthony et alii, 2005). Çocuk bu karmaşık sosyal ortamda bağlanma ilişkisini öncelikle öğretmeniyle kurmaktadır. Çocuğun öğretmeniyle olan bağlanma ilişkisi onun yaşayacağı sosyal çatışmalarla baş etmesini ve okula uyumu kolaylaştırarak akademik ve sosyal başarısına katkı sağlayacaktır (Cottone et alii, 2008). Okul öncesi yaşlardaki çocuklar, öğretmenleriyle olan etkileşimlerini akranlarıyla olan etkileşimlerinden daha fazla önemsemektedir. Bu nedenle bu yaş çocuklarının okuldaki davranışlarında öğretmenle kurduğu etkileşim daha ön plandadır (Demirhan, 2011). Myers (2009)'in araştırmasında okul öncesi dönemdeki çocukların öğretmenle olan ilişkilerinin çocukların duygusal problemleri ile doğrudan ilişkili olduğu belirtilmektedir.

Çocukların yaşamında bu denli önemli olan okul öncesi öğretmenlerin sahip olması gereken özellikler üzerine yapılan araştırmalarda; çocukların bilişsel, dil, sosyal ve duygusal gereksinimlerini gidermeye istekli olma (Hansen, \& Feldhusen, 1994), çocuk merkezli öğrenme 
fırsatlarını yaratma (Davalos, \& Griffin, 1999), aktif öğrenme ve araştırmaya özendirme (Whitlock, \& DuCette, 1989; Feldhusen, 1991; Goertz, \& Phemister, 1994) gibi bireysel özelliklerin yanında, çocukların eleştirel düşünme becerisini geliştirici stratejiler uygulama (Nelson, \& Prindle, 1992) ve çocukların farklı bireysel özelliklerini destekleyen ilgi ve gereksinimlerini karşılayan programlar hazırlayıp uygulayabilme (Nelson, \& Prindle, 1992; Bangel et alii, 2010) gibi birtakım mesleki yeterlilikler öne çıkarılmaktadır. Ancak okul öncesi sınıf ortamında çocukların ilgi ve ihtiyaçlarına cevap verilebilmesi, sınıf yönetimini oluşturulabilmesi, zevkli ve eğlenceli öğrenme ortamlarının sunulabilmesi için çocukları sevmek daha da önemlidir (Ergün, \& Özdaş 1999). Bu nedenle henüz gelişme çağında olan ve olgunlaşmamış "çocuğu sevmek" öğretmenlerin sahip olması gereken özelliklerin en başında gelmelidir (Gelbal, \& Duyan, 2010). Okul öncesi öğretmenlerden beklenen de gelişimsel olarak kritik dönemde olan çocukların fiziksel, bilişsel, dilsel ve sosyal-duygusal olarak (Erden, \& Duyan, 2011) gelişimsel ve eğitsel ihtiyaçlar karşılanırken öncelikle çocukların en temel gereksinimleri olan sevgi ve ilgi ihtiyaçlarını karşılanması gerekmektedir.

Çocuklarla çalışılan meslek alanlarında yapılan araştırmalar incelendiğinde mesleği icra edenlerin çocuk sevme eğilimi konusunun nicel ya da nitel olarak ortaya konulan çalışmaların çok yetersiz olduğu görülmüştür. Yaşamın en kritik evresinde görev alacak olan okul öncesi öğretmen adaylarının çocuk sevme eğilimlerine yönelik olarak yapılmış herhangi bir alan çalışmasına ise rastlanılmamıştır. Çocuğun yaşamında her anlamda kritik öneme sahip olan okul öncesi öğretmen adaylarının çocuk sevme düzeyinin incelenmesinin gerekli olduğu düşüncesinden hareketle planlanan bu çalışmada, okul öncesi öğretmen adaylarının çocukları sevme eğilimlerinde etkili olan değişkenleri belirlemek amaçlanmıştır. Bu amaç kapsamında okul öncesi öğretmen adaylarının yaş, cinsiyet, üniversiteye girişte tercih sıralaması, en uzun ikamet ettiği yerleşim yeri ve sınıf düzeyi gibi değişkenlerin çocuk sevme eğilimlerinde etkili olup olmadığı incelenmiştir.

\section{Yöntem}

Kesitsel bir araştırma olan bu çalışma, nicel araştırma tekniğiyle gerçekleştirilmiştir. Araştırmanın çalışma grubunu, 2011-2012 Eğitim öğretim yılında Akdeniz Üniversitesi ve Çukurova Üniversitesi’nin Eğitim Fakültesi Okul Öncesi Öğretmenliği Lisans Program öğrencileri oluşturmaktadır. Örneklemini ise her iki Üniversitenin birinci ve ikinci örgün öğretiminde öğrenimini devam ettiren okul öncesi öğretmen adayları arasından, gönüllülük esasına göre seçilen toplam 610 (Akdeniz Üniversitesi'nden n=320 \% 52.4, Çukurova Üniversitesi'nden n=290, \% 47.5) okul öncesi öğretmen adayı oluşturmaktadır. Uygulama yapılan öğretmen adayları özellikle seçilmiş olmayıp, araştırmacının ulaşabildiklerinden oluşturulduğu için araştırma sonuçları yalnızca uygulama yapılan okul öncesi öğretmen adaylarına genellenebilmektedir.

\section{Veri Toplama Yöntemi}

Veri toplama aracı olarak, araştırmacı tarafından araştırmanın amacı doğrultusunda hazırlanmış kişisel bilgi formu ve Barnett Çocuk Sevme Ölçeği kullanılmıştır.

Kişisel Bilgi Formu: öğretmen adaylarının yaş, cinsiyet, okul öncesi öğretmenliğini tercih sırası, mezun olduğu lise türü gibi bazı sosyo-demografik özelliklerine ilişkin sorular yer almaktadır. Barnett Çocuk Sevme Ölçeği: Barnett, \& Sinisi, (1990) tarafından insanların çocuklara yönelik tutumlarını ölçme amacıyla geliştirilen ölçeğin Türkiye için güvenirlik ve geçerlik çalışması Duyan, \& Gelbal (2008) tarafından yapılmıştır. Ölçeğin test-tekrar test güvenirliği 0.854 ve iç tutarlılık katsayısı 0.92 olarak belirlenmiştir. Ölçek 14 maddeden oluşmaktadır ve her bir maddede belirtilen düşünceye, bireylerden "Hiç katılmıyorum" yanıtından, "Tamamen katılıyorum" 
yanıtına kadar değişkenlik gösteren yedi derecede görüş bildirmeleri istenmektedir. Ölçekten alınan yüksek puanlar, insanların çocukları daha fazla sevdikleri; düşük puanların ise çocukları sevme düzeyinin düşük olduğu anlamına gelmektedir.

Araştırma verilerinin analizinde değişkenlerin yapısına ve verilerin özelliklerine uygun olacak şekilde parametrik ve parametrik olmayan istatistiksel yöntemler kullanılmıştır. Çocuk sevme ölçeğinden alınan puan sürekli değişkendir ve araştırmanın bağımlı değişkeni olarak ele alınmıştır. Bağımlı değişkenin evrendeki dağılımının normal olduğu kabul edilmektedir. Araştırmanın bağımsız değişkenini ise öğretmen adaylarının demografik özellikleri oluşturmaktadır. Öğretmen adaylarının demografik özelliklerine göre çocuk sevme ölçeğinden aldıkları puanların aritmetik ortalamaları karşılaştıılmıştır. Karşılaştırmada bağımsız değişkenin kategori sayısı iki olduğunda " $t$ " testi; kategori sayısı ikiden fazla olduğu durumlarda ise " $F$ " testi kullanılmıştır. F testinde anlamlı farklılık bulunduğunda, ikili karşılaştırmalar için “ $L D S$ ” testi kullanılmıştır.

\section{Bulgular}

Araştırmanın bulguları, öğretmen adaylarının demografik özellikleri ve demografik değişkenlere göre çocuk sevme eğilimleri olmak üzere iki bölüm olarak incelenmiştir.

Araştırmaya katılan adayların \% 87,4'ü $(n=534)$ kız, \% 12,6 $(n=76)$ erkektir. Adayların \% 35,5'i 18-20 yaş arasında, \% 34,7'i 21-23 yaş arasında ve \% 10,6'ı da 24 yaş ve üzerindedir. Adayların üniversiteye girişte tercih sıralamasına bakıldığında ise \% 55,3'ünün ilk, \% 36,5’inin ilk on, \%8,0'nin da son tercihinin okul öncesi öğretmenliği olduğu belirlenmiştir. Adayların \% 22,9’u birinci sınıf, \% 26,5' ikinci sınıf, \% 22,9’u üçüncü sınıf, \% 27,5’i de dördüncü sinıfta bulunmaktadır. Adayların \% 73,3’ü örgün öğretim, \% 26,5'de ikinci öğretim programına devam etmektedir. Okul öncesi öğretmen adaylarının daha önce en uzun süre yaşadığı yere göre dağılımları incelendiğinde, adayların \% 73,6’sının köy ya da kasaba, \% 26,4'ününde ilçe ya da ilde uzun süre yaşamış olduğu görülmüştür.

Tablo 1'de demografik değişkenlere göre okul öncesi öğretmen adaylarının çocuk sevme durumuna ilişkin araştırma bulgularına yer verilmiştir. Bu tabloda demografik değişkenler olarak cinsiyet, yaş, adayın en uzun süre yaşadığı yerleşim birimi, okul öncesi öğretmenliğini tercih etme sıralaması, kayıtlı olduğu sınıf olarak ele alınmıştır. Bu değişkenlere göre okul öncesi öğretmen adaylarının çocuk sevme eğilimlerinin farklılaşıp farklılaşmadığı incelenmiştir.

Tablo 1. Okul Öncesi Öğretmen Adaylarının Demografik Özelliklerine Göre Çocuk Sevme Durumu

\begin{tabular}{|l|c|c|c|c|}
\hline \multirow{2}{*}{ Çalışma Grubunun Özellikleri } & \multicolumn{5}{|l|}{ Çocuk Sevme Puanı } \\
\cline { 2 - 5 } & $\mathrm{N}$ & $\mathrm{X}$ & $\mathrm{SS}$ & \multirow{2}{*}{ İstatistik } \\
\hline Cinsiyet & & & & \multirow{2}{*}{$\mathrm{t}=3,359^{* *}$} \\
\hline Kız & 534 & 83,28 & 13,19 & \\
\hline Erkek & 76 & 78,80 & 10,49 & $\mathrm{~F}=10,783$ * \\
\hline Yaş & & & & $\begin{array}{c}\text { (18-20 ile 21-23 ve 24 yaş ve üzeri } \\
\text { anlamlı) }\end{array}$ \\
\hline $18-20$ & 333 & 80,618 & 14,896 & $\mathrm{t}=, 003$ \\
\hline $21-23$ & 212 & 85.797 & 9,779 & \\
\hline 24 ve üzeri & 67 & 86,3446 & 83842 & \\
\hline En uzun yaşadığı yerleşim birimi & & & & \\
\hline Köy- kasaba & 450 & 82,702 & 13,845 & \\
\hline İlçe-İl & 160 & 82,719 & 10,1231 & \\
\hline Tercih sırası & & & & \\
\hline & & & & \\
\hline
\end{tabular}




\begin{tabular}{|l|c|c|c|c|}
\hline İlk Tercih & 338 & 83,591 & 14.433 & $\mathrm{~F}=, 843$ \\
\hline İlk on tercih & 233 & 82,139 & 11,183 & \\
\hline Son Tercih & 49 & 82,719 & 9,250 & \\
\hline Devam ettiği sınıf düzeyi & & & & $\mathrm{F}=11.867$ ** \\
\hline 1.Sinıf & 140 & 78,257 & 14.903 & (1.sinıf ile 2,3 ve 4 sinıflar anlamlı) \\
\hline 2.Sınıf & 162 & 83,642 & 10,901 & \\
\hline 3.Sinıf & 140 & 83.457 & 14.130 & \\
\hline 4. Sinıf & 168 & 86.719 & 12,964 & \\
* $<0.05, \mathrm{p}<0.001$ &
\end{tabular}

Yapılan analiz sonucunda okul öncesi öğretmen adaylarının cinsiyete göre çocuk sevme eğilimleri arasında istatistiksel olarak anlamlı bir fark olduğu görülmüştür $(t=3,359, \mathrm{p}<0.05)$. Grupların cinsiyete ilişkin ortalama puanlarına bakıldığı zaman bu farkın kız öğretmen adaylar lehine olduğu görülmektedir $\left(\bar{X}_{\mathrm{K} 1 z}=83,28\right.$ ve $\left(\bar{X}_{\text {Erkek }}=78,80\right)$. Bu bulgulara göre kız öğretmen adayların çocuk sevme eğilimlerinin erkek öğretmen adaylarına göre yüksek olduğu söylenebilir.

Yapılan istatistiksel analiz sonucunda okul öncesi öğretmen adaylarının yaş değişkenine göre çocuk sevme eğilimi puanları arasında anlamlı bir fark olduğu görülmüştür ( $F=10,783$, $\mathrm{p}<.001)$. Farklılığın hangi gruplar arasında olduğunu belirlemek için uygulanan LDS çoklu karşılaştırma testi sonucunda 24 yaş ve üzeri öğretmen adayı grubu lehine istatistiksel açıdan $(\mathrm{p}<.05)$ anlamlı bir farklılık saptanmıştır. Bu bulgular 24 yaş ve üzerinde olan okul öncesi öğretmen adaylarının çocuk sevme eğilimi puanlarının $\left(\bar{X}_{24}\right.$ ve üzeri $\left.==86,719\right)$ diğger yaş aralığında olanlara göre $\left(\bar{X}_{21-23 \text { yas }}=85.797\right.$ ve $\left.\bar{X}_{18-20 \text { yas }}=80,618\right)$ daha yüksek olduğunu göstermektedir. Bu bulguya göre yaş arttıkça öğretmen adaylarının çocuk sevme eğilimlerinde olumlu yönde bir artışın olduğu söylenebilir.

Yapılan analiz sonucunda okul öncesi öğretmen adaylarının sınıf düzeyine göre çocuk sevme eğilimi puanları arasında istatistiksel olarak anlamlı bir fark olduğu saptanmıştır ( $\mathrm{F}=11.867, \mathrm{p}<.005)$. Farklılığın hangi gruplar arasında olduğunu belirlemek için uygulanan LDS çoklu karsılaştırma testi sonucunda dördüncü sınıf öğretmen adayı grubu lehine istatistiksel açıdan ( $\mathrm{p}<.05)$ anlamlı bir farklılık saptanmıştır. Bu bulgu, dördüncü sınıf öğretmen adaylarının çocuk sevme eğilim düzeyinin $\left(\bar{X}_{\text {Dördüncü smıf }}==86,719\right)$ diğer sinıflara göre $\left(\bar{X}_{\text {Üçüncü smnf }}=83,457\right.$, $\bar{X}_{\text {İknci smnf }}=83,643$ ve $\left.\bar{X}_{\text {Birinci smif }}=78,257\right)$ daha yüksek olduğunu göstermektedir. Bu bulguya göre sınıf düzeyi arttıkça öğretmen adaylarının çocuk sevme eğilimlerinde olumlu yönde bir değişimin gerçekleştiği söylenebilir.

Yapılan analiz sonucunda okul öncesi öğretmen adaylarının en uzun yaşadığı yer ( $\mathrm{t}=, 003$, p> 0.05) ve adayları üniversiteye girişte okul öncesi öğretmenliği mesleğini tercih etme sıralaması $(F=, 843, p>0,05)$ değişkenlerine göre çocuk sevme eğilimi düzeyi arasında anlamlı bir farklılığın olmadığı görülmüştür. Bu bulgular, okul öncesi öğretmen adaylarının çocuk sevme eğiliminde mesleki tercih sıralaması ve en uzun süre yaşanılan birim değişkenlerinin etkili olmadığını göstermektedir.

\section{Tartışma}

Okul öncesi eğitimi öğretmen adaylarının çocuk sevme eğilimlerini belirlemek amacıyla yapılan bu araştırmada; cinsiyet, yaş ve öğrenim görülen sınıf düzeyi değişkenlerinin öğretmen adaylarının çocuk sevme eğiliminde etkili birer değişken olduğu, ancak en uzun süre yaşanılan birim ve mesleki tercih sırası değişkenlerinin çocuk sevme eğilimden etkili olmadığı belirlenmiştir.

Okul öncesi öğretmenliği öğretmen adaylarının çocuk sevme eğiliminde cinsiyete göre anlamlı farklılıklar olduğu saptanmıştır $(p<0,05)$. Bu farkın kız adaylar lehine olduğu ve kızların erkek adaylara göre çocuk sevme eğilimi puanlarının daha yüksek olduğu görülmüştür. Türkiye 
örnekleminde farklı öğretmenlik alanlarında yapılan araştırmalarla ilgili alan yazın incelendiğinde, araştırmadan elde edilen bulgularla örtüşen ya da karşıtlık gösteren çalışmalara rastlanmaktadır. Örneğin, Özkara (2013)'nın sınıf öğretmenliği adaylarıyla yaptığı çalışmasında, aday öğretmenlerin çocuk sevme eğiliminde cinsiyetin etkili bir değişken olduğu görülürken, Gelbal, \& Duyan (2010)'ın yaptığı çalışmada çocuk sevme eğiliminde cinsiyetin etkili bir değişken olmadığı görülmektedir. Çimen (1988)’in aktarımına göre, küçük yaşlardan itibaren kültürlerin bazı meslekleri birinci derecede kadınlara bazılarını ise erkeklere özgü sayması, toplum tarafından kadınlara genellikle bu mesleğin ideal olduğu yönünde telkinlerin yapılması gibi nedenlerle erken yaşlarda örtük öğrenme yoluyla kız adayların öğretmenlik mesleğine ilgilerini uyandırmış olabilir.

Ayrıca aday öğretmenlerle yapılan empatik eğilim araştırmalarında kızların empati düzeyinin erkeklere oranla daha yüksek olduğu yönünde bulgulara da rastlanmaktadır. Bu bulgularda kız öğrencilerin erkeklere oranla daha duygusal, daha hassas yapıya sahip olarak yetiştirilmelerinden kaynaklandığı savının ileri sürüldüğü (Gülveren, 2007) görülmektedir. Bu bilgiler ışığında erkek öğretmen adaylarına göre kız öğretmen adaylarının çocuklara daha koruyucu ve kollayıcı yaklaşım sergileme eğilimlerinin erken yaşlardan itibaren özdeşleştirilmiş olmalarından kaynaklandığı da düşünülebilir.

Her ne kadar birincil işi öğretmek olan aday öğretmenin cinsiyetinin çocukları sevme açısından bir fark oluşturmaması gerektiği düşünülse de (Gelbal, \& Duyan, 2010) okul öncesi dönemdeki çocuklar aile ortamından daha yeni ayrıldığından kız öğretmen adaylarının bu çocuklara yaklaşımında daha koruyucu ve kollayıcı yaklaşım sergilemeye eğilimli olduğu görülmektedir.

Yaş durumuna göre 24 yaş ve üzeri grubundaki öğretmenlerin çocuk sevme puanlarının en yüksek olduğu saptanmıştır. Bu yaş dönemi ergenlikten çıkmış ve yetişkinlik sorumluluklarının farkına varılan dönemi kapsamaktadır. Ergenlikte kimlik duygusunu yerleştiren birey, başkalarıyla yakınlıklar, dostluklar kurmanın ve daha geniş ilişkiler kurarak topluma karışmanın, iş ve kariyerin önemli olduğunun bilincindedir. Bu yaşlarda bireyler güvenli bir şekilde sevgiyi verme ve alma gücüne sahip olurlar. Ayrıca aday öğretmenlerin yaşları ilerledikçe deneyimlerinin artması sonucu olaylara bakış açıları değişiyor ya da tahammül etme düzeyleri de artıyor olabilir. Sonuç olarak, 24 yaş ve üzerinin çocuk sevme puanlarının yüksek, yaş düştükçe çocuk sevme puanlarının düşük çıkmasının gelişimsel bakış açısıyla uyumlu olduğu değerlendirilebilir (Gelbal, \& Duyan, 2010).

Aday öğretmenlerin üniversiteye girişte tercih sıralamalarına göre çocuk sevme puanları arasında fark bulunmamaktadır. Adaylar hangi sırada tercih yapmış olursa olsun öğrenim yaşantısı sırasında almış oldukları eğitim ve bilinçlenme onların mesleğe ve mesleğin gerekliliklerine karşı bilinçlenmesini sağlamış, çocuklara karşı ilgisini artırmış olabilir. Çocukları sevip sevmeme durumu aday öğretmenin mesleki yaşama bakışı ve kişilik özellikleriyle de yakından ilişkili olabilir. Okul öncesi öğretmenliğini tercih sırasının etkisiz oluşunun nedeni, aday öğretmenlerin eğitim yaşantısına başladığında derslerinde ya da uygulamalarında edindikleri idealizmin meslekteki seçimlerinin kişilik özelliklerine uygun olmasından da kaynaklanıyor olabilir. Öğrenim deneyimleri süresi arttıkça aday öğretmenlerin okul öncesi öğretmenliği mesleğine bakış açıları da farklılaşmış olabilir.

Araştırmadan elde edilen bir diğer bulguda okul öncesi öğretmen adaylarının sınıf düzeylerine göre çocuk sevme eğilimlerinin farklılaşmakta olduğudur $(\mathrm{p}<0,05)$. Adayların sınıf düzeyi yükseldikçe çocuk sevme eğilimi puanlarının artışının doğru orantılı olduğu saptanmıştır.

Tüm öğretmenlik alanlarında olduğu gibi okul öncesi eğitimi öğretmenlerinden beklenen de çocukların fiziksel, entellektüel, duygusal ve sosyal gelişimsel farklılıklarını anlamaları, çocuk- 
ları savunmaları, onlara gerekli sevgi ve ilgiyi göstermeleridir (Erdem, \& Duyan, 2011). Bu beklentilerin gerçekleşebilmesi için birçok ülkede olduğu gibi Türkiye'deki öğretmen yetiştirme programı kapsamında aday öğretmenlere sınıf ortamını fark ettirme ve çocuklarla olan etkileşimleri gözlemleme gibi olanaklar sağlanmaktadır. Bu olanaklar adayların psikolojik ve sosyolojik faktörlerin farkındalığını kazanmasına yönelik deneyimler elde etmelerine (Goodlad et alii, 1990; Barone et alii, 1996; Korthagen, 2001) ve hizmet vereceği sosyal kitle olan çocukları daha yakından tanımalarına fırsat vermektedir. Böylece adaylar mesleki yaşama başladığında gelişimsel ya da sosyo-kültürel farklılıklara sahip olan çocuklarla çalışma imkanı bularak, çocukların bireysel kapasitesi ve kültürel normlarının farklılıklarını da sezinleyebilme (DarlingHammond, 2000) olanaklarına sahip olurken, çocuklarla çalışma konusunda kendine ve mesleğine yönelik temel inancını da oluşturmaktadır. Özellikle mesleki eğitim yaşantısının sonuna doğru adayların yoğun uygulamalara katılmaları, çocuklarla ilgili gönüllü çalışmalarda bulunmaları, çocuklarla sık sık birarada olabilecekleri ortamların artması adayların çocukları tanıma ve onlarla bağ oluşturma olanağını artırmış olabilir.

Sonuç olarak kaliteli ve başarılı eğitimin mihenk taşlarından biri öğretmendir. Bu nedenle öğretmenin mesleki doyum sağlamasında, nitelikli bir eğitim süreci planlayarak uygulamasında çocuklarla bir arada olmaya karşı ilgi, istekliliği ve çocuklara olan sevgisi en önemli unsurlardan biri olacaktır. Bu nedenle üniversitelere öğretmen adayı alınırken çocuklarla çalışmaya ilgisi olan ve çocukları seven bireylerin tercih edilmesi yönünde çalışmaların yapılması öngörülebilir.

\section{KAYNAKÇA}

Anthony, L., Gutermuth, A., Bruno J., Glanville, D. N., Naiman, W., Daniel, C., \& Shaffer, S. (2005). "The Relationships Between Parenting Stress, Parenting Behaviour and Preschoolers' Social Competence and Behaviour Problems in the Classroom”. Infant and Child Development, 14, 133-154.

Bangel, N. J., Moon, S. M., \& Capobianco, B. M. (2010). "Preservice Teachers' Perceptions and Experiences in a Gifted Education Training Model Gifted Child”. Quarterly, 54 (3), 209-221.

Barnett, M. A., \& Sinisi, C. S. (1990). "The initial validation of a Liking of Children Scale”. Journal of Personality Assessment, 55, 161-167.

Bishop, W. E. (1980). "Successful Teachers of The Gifted”. Eds. In Renzulli, J. S., \& Stoddard, E. P., Under one cover: Gifted and Talented Education in Perspective, 152-160. Reston, VA.

Barone, T., Berliner, D. C., Blanchard, J., Casanova, U., \& McGowan, T. (1996). "A Future for Teacher Education”. Ed. J. Siluka. Handbook of Research on Teacher Education, (2nd ed.), 1108-1149. New York: Macmillan.

Çimen, M. (1988). Cinsiyet ve Bazı Sosyo-Ekonomik Değisskenlerin, Lise Öğrencilerinin Mesleki İlgilerine Etkisi. Yayımlanmamış Yüksek Lisans Tezi. Hacettepe Üniversitesi, Ankara.

Çermik, H. Doğan, B., \& Şahin, A. (2010). "Sınıf Öğretmenliği Öğretmen Adaylarının Öğretmenlik Mesleğini Tercih Sebepleri”. Pamukkale Üniversitesi Eğitim Fakültesi Dergisi, 28 (II), 201-212

Cottone, E. A., Mashburn, A., \& Rimm-Kaufman, S. E. (2008). "Relationships Between Teachers and Preschoolers Who are At Risk: Contribution of Children's Language Skills, Temperamentally Based Attributes, And Gender”. Early Education And Development, 19 (4), 600-621.

Darling-Hammond, L. (2000). "How Teacher Education Matters". Journal of Teacher Education, 51 (3), 166-173.

Davalos, R., \& Griffin, G. (1999). “The Impact of Teachers' Individualized Practices on Gifted Students in Rural, Heterogeneous Classrooms". Roeper Review, 21 (4), 308-314.

Demirel,Ö.(2006).Öğretim İlke ve Yöntemleri Öğretme Sanatı. Ankara: Pegem A Yayıncllı.

Downing, J. E., Ryndak, D. L., \& Clark, D. (2000). "Paraeducators in Inclusive Classrooms: Their Own Perceptions”. Remedial and Special education, 21, 171-181.

Durak Demirhan, T. (2011). “Okul Öncesi Çocuk ve İlk Öğretmeni” Eds. M. Uluğ, \& G. Karadeniz. Okul 
Öncesi Çocuk ve... Ankara: Nobel Yayıncılık.

Duyan, V., \& Gelbal, S. (2008). “Barnett Çocuk Sevme Ölçeği’ni Türkçeye Uyarlama Çalışması”. Eğitim ve Bilim Dergisi, 33, 40-48.

Ekinci, Ö. (2009). Öğretmen Adaylarının Empatik ve Eleştirel Düşünme Eğilimlerinin İncelenmesi. Yayınlanmış Yüksek Lisans Tezi. Çukurova Üniversitesi Sosyal Bilimler Enstitüsü, Adana.

Ergün, M., \& Özdaş, A. (1999). “Okul Gözlemi ve Uygulama Çalışmalarının Öğretmen Adayları Üzerindeki Etkisi”. AKÜ Sosyal Bilimler Dergisi, 3, 115-119.

Erdem, Y., \& Duyan, V. (2011). "A Determination of The Factors that Aff Ect the Level of Pediatric Nurses’ Liking of Children”. Turk J Med Sci, 41 (2), 295-305.

Eskicumalı, A. (2002). “Eğitim, Öğretim ve Öğretmenlik Mesleği” Ed. Yüksel Özden. Öğretmenlik Mesleğine Giriş, 14-25. Ankara: Pegem A Yayıncılık.

Feldhusen, J. F. (1991). “Full-Time Classes for Gifted Youth”. The Gifted Child Today, 14 (5), 10-13.

Gelbal, S., \& Duyan, V. (2010). “Examination of variables affecting primary school teachers” state of liking of children”. Hacettepe Üniversitesi Eğitim Fakültesi Dergisi, 38, 127-137.

Gülveren, H. (2007). Eğitim Fakültesi Öğrencilerinin Eleştirel Düşünme Becerileri ve Bu Becerileri Etkileyen Eleştirel Düşünme Faktörler. Yayınlanmamış Doktora Tezi, Dokuz Eylül Üniversitesi Eğitim Bilimleri Enstitüsü, İzmir.

Goodlad, J. I., Soder, R., \& Sitronik, K. A. (1990). Places where Teachers are Taught. San Francisco: Jossey-Bass.

Hansen, J. B., \& Feldhusen, J. F. (1994). “Comparison of Trained and Untrained Teachers of Gifted Students”. Gifted Child Quarterly, 38 (3), 115-121.

Hughes, J. N., Cavell, T. A. and Jackson, T. (1999). "Influence of the Teacher-Student Relationship on Childhood Conduct Problems: a Prospective Study”. Journal of Clinical Child Psychology, 28, (2), 173-184.

Kavcar, C. (1999). “Nitelikli Öğretmen Sorunu”. Eğitimde Yansımalar: V. 21, 267-279. Yüzyılın Eşiğinde Eğitim Sistemi Ulusal Sempozyumu. Ankara: Öğretmen Hüseyin Hüsnü Tekışık Eğitim Araştırma-Geliştirme Merkezi Yayını.

Korthagen, F. A. J. (2001). "Linking Practice and Theory: The Pedagogy of Realistic Teacher Education. Lawrence Erlbaum Associates”. Inc. Publishers 10 Industrial Avenue.

Lasley, T. (1980). "Preservice Teacher Beliefs about Teaching”. Journal of Teacher Education, 31 (4), 38-41.

Langford, D. P. (1999). Eğitimde Kalite Yönetimi. İstanbul: KalDer Yayınları.

Marso, R. N., \& Pigge, F. L. (1994). "Personal and family characteristics associated with reasons given by teacher candidates for becoming teachers in the 1990's: Implications for the recruitment of teachers”. A paper presented at the annual conference of the Midwestern Educational Research Association”. Chicago, October, 12-15.

Myers, S. S. (2009). "Examining associations between effortful control and teacher-child relationships in relation to head start children's socioemotional adjustment”. Early Education And Development, 20 (5), 756-774.

Nelson, K. C., \& Prindle, N. (1992). “Gifted teacher competencies: Ratings by rural principals and teachers compared”. Journal for the Education of the Gifted, 15 (4), 357-369.

Özkara, Y. (2013). “The Profile of Pre-Service Teachers’ Tendencies Towards Liking of Children”. Internatıonal Journal of Academic Research Part B. 5 (3), 228-232.

Tomlinson, P. (1995). “Can competence profiling work for effective teacher preparation? Part I: General issue”. Oxford Rewiew of Education, 21 (2), 179-194.

Veenman, S. (1984). "Perceived Problems of Beginning Teachers". Review of Educational Research. 54 (2), 143-178.

Whitlock, M. S., \& DuCette, J. P. (1989). “Outstanding and Average Teachers of the Gifted: A Comparative Study”. Gifted Child Quarterly, 33 (1), 15-21.

Weinstein, C. S. (1988). "Preservice teachers' expectations about the first year of Teaching”. Teaching \& Teacher Education, 4 (1), 31-40. 